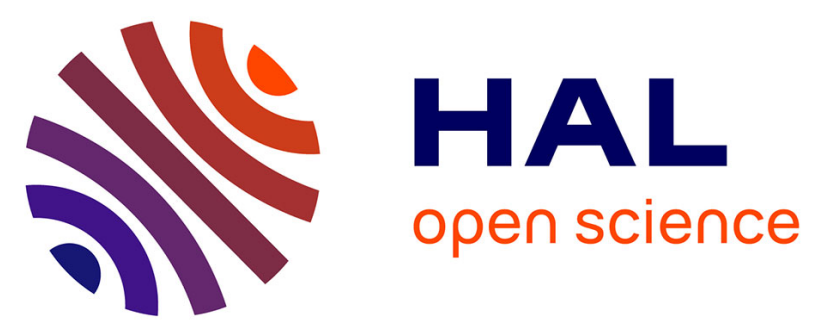

\title{
Simulation and experimentation of an RFID system in the UHF band for the reliability of passive tags
}

Sanae Taoufik, Farid Temcamani, Ahmed Eloualkadi, Bruno Delacressonniere, Pascal Dherbécourt

\section{- To cite this version:}

Sanae Taoufik, Farid Temcamani, Ahmed Eloualkadi, Bruno Delacressonniere, Pascal Dherbécourt. Simulation and experimentation of an RFID system in the UHF band for the reliability of passive tags. Lecture Notes in Electrical Engineering, Springer, 2016, 1, pp.35-43. 10.1007/978-3-319-30301-7_5 . hal-01341760

\author{
HAL Id: hal-01341760 \\ https://hal.science/hal-01341760
}

Submitted on 4 Jul 2016

HAL is a multi-disciplinary open access archive for the deposit and dissemination of scientific research documents, whether they are published or not. The documents may come from teaching and research institutions in France or abroad, or from public or private research centers.
L'archive ouverte pluridisciplinaire HAL, est destinée au dépôt et à la diffusion de documents scientifiques de niveau recherche, publiés ou non, émanant des établissements d'enseignement et de recherche français ou étrangers, des laboratoires publics ou privés. 


\title{
Simulation and experimentation of an RFID system in the UHF band for the reliability of passive tags
}

\author{
SanaeTaoufik $^{(1,2)}$, Ahmed El Oualkadi ${ }^{(1)}$, FaridTemcamani ${ }^{(3)}$, Bruno \\ Delacressonniere $^{(3)}$, Pascal Dherbécourt ${ }^{(2)}$ \\ (1) Laboratory of Information Technology and Communication \\ National School of Applied Sciences of Tangier, Abdelmalek Essaadi university, Morocco \\ (2) Materials Physics Group, UMR CNRS 6634 university of Rouen \\ Avenue de l'université B.P 1276801 Saint Etienne du Rouvray, France \\ Email: sanae.taou@gmail.com \\ (3) ECS-Lab EA3649 National School of Electronics and its applications \\ 6 Avenue du Ponceau 95014 Cergy Pontoise, France
}

\begin{abstract}
This paper presents the simulation of a UHF RFID (Radio Frequency Identification) system for passive tags, using Advanced Design System software from Agilent Company. Temporal measurements based on a commercial RFID reader are achieved which permit to analyze and to validate the principles of communication between the reader and the tag. Also a test bench is developed to evaluate the effects of high temperature on the reliability of passive UHF RFID tags. The obtained test results show that the thermal storage has a marked effect on the performances of the RFID tags.
\end{abstract}

Keywords: RFID, Passive tag, UHF band, simulation ADS, Reliability.

\section{Introduction}

Radio Frequency Identification (RFID) is a generic term used to describe a system which transmits an object or a person identity by using a radiofrequency link. Nowadays, the RFID technologies are used in many domains such as transport, medical treatment, smart cards...

Generally, RFID systems consist of two basic elements, a reader and a tag. The reader is composed of a high-frequency module, a control unit and an antenna [2]. The tag attached to an object, consists an antenna and a silicon chip, containing an identification code. According to the working frequency, RFID systems are classified in four frequency bands: low frequencies (LF) around $125 \mathrm{kHz}$, high frequencies (HF) at $13.56 \mathrm{MHz}$, ultra-high frequencies (UHF) at $860-960 \mathrm{MHz}$, and the microwaves at $2.4 \mathrm{GHz}$ [3]. For the LF and HF systems, the communication distance is shorter than one meter. For UHF RFID systems, it reaches around five meters. The RFID systems are also classified according to the tag technology. Active RFID tags have a transmitter and their own power source (typically a battery). The power source is used 
to run the microchip's circuitry and to broadcast a signal to a reader. Passive tags have no battery. Instead, they draw power from the reader, which sends out electromagnetic waves that induce a current in the tag's antenna [4]. This paper shows the design of a passive UHF RFID system. The system respects the EPC class1 Generation2 which is an air interface protocol first published by EPC global in 2004, it defines the physical and logical requirements for an RFID system of interrogators and passive tags, operating in the $860 \mathrm{MHz}-960 \mathrm{MHz}$ UHF range. Over the past decade, EPC class1 Gen2 has been considered as the standard for UHF implementations across multiple sectors, and is at the heart of more and more RFID implementations [5].

\section{Description of the RFID system architecture}

The reader consists of a transceiver, with an antenna that communicates with a passive tag. The tag returns its identification code by retro-modulation. The RFID system, shown in figure 1, is simulated using the co-simulation between the numeric front end and the radio front end.

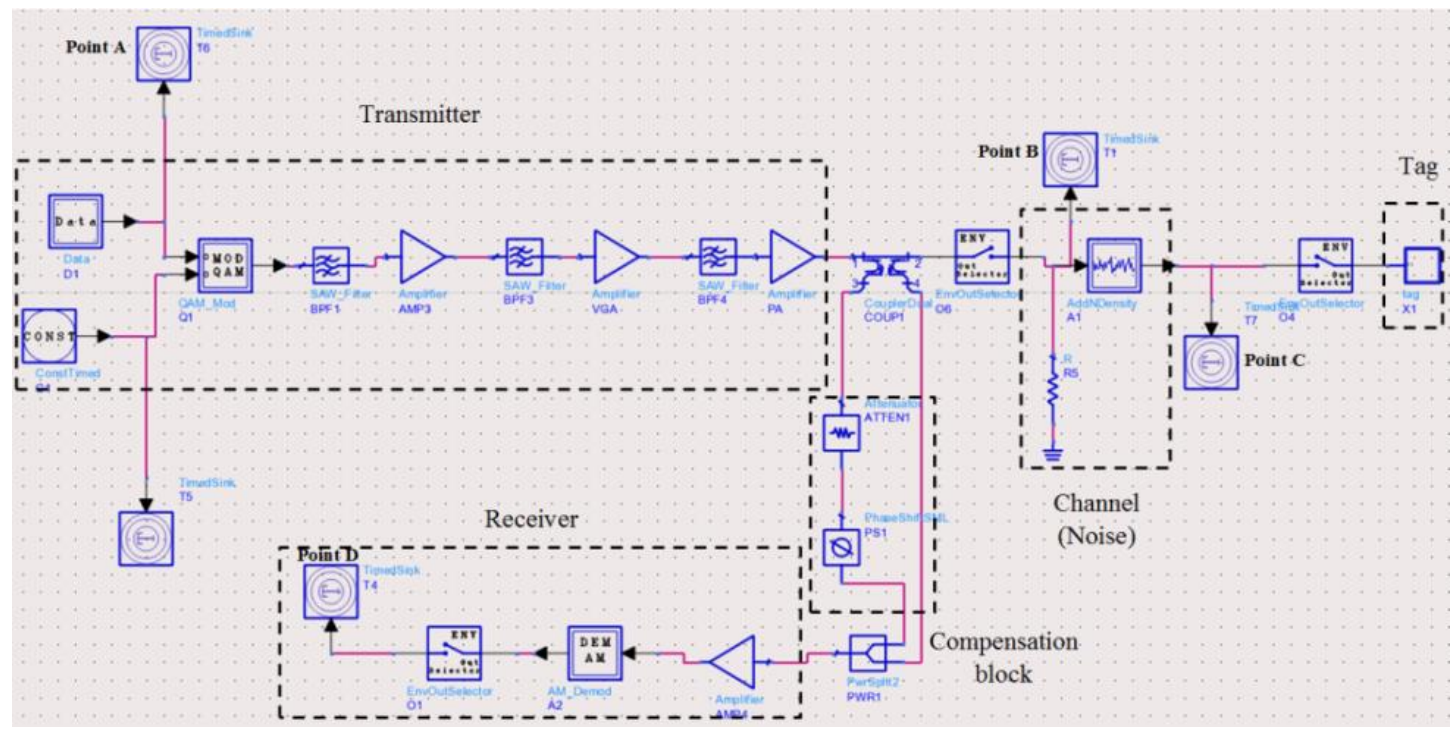

Fig. 1. Block diagram of the RFID communication system.

The transmitter part in the figure 1, is mainly made up of a digital data source and an ASK (Amplitude Shift Keying) modulator with internal oscillator. Filtering and amplification stages are also included, with a bandwidth in the (860-960) MHz range. Filters are used to reject the out-of-band spectrum.

The receiver part is also presented in figure 1 . The received signal is first amplified by a low-noise amplifier (LNA), and then filtered and demodulated by an ASK demodulator. The emitted and received signals are separated by a directional coupler. 
A compensation block is implemented to attenuate and phase shift the signal in order to reduce the isolations defects at reception [6].

The communication channel defect is modelled by an additive Gaussian filter to introduce sources of noise representing the environment.

Considering EPC Class 1 protocol, tags respond to the reader by retro-modulation sending the encode form signal shown in Figure 2. Two transitions are observed for a binary zero and four transitions are observed for a binary one during one elementary cell. The data rate of the returned signal is $140.35 \mathrm{Kbps}$ (in North America) and 30 Kbps (in Europe) 7].

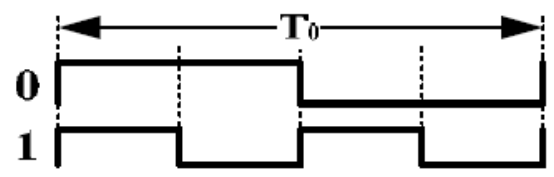

Fig. 2. EPC Class1 protocol signal encoding.

\section{Simulation results}

In this section, significant simulation results for each part of the system are presented. Figure 3 shows the simulation of PRBS (Pseudo Random Binary Sequence) data generated by the data-source from the reader transmitter (point A on Figure 1). The data rate is chosen equal to $100 \mathrm{Kbit} / \mathrm{s}$ corresponding to a bit time equal to $10 \mu \mathrm{s}$. Figure 4 shows the modulated signal (point B on Figure 1) using DSB-ASK (Doubleside band amplitude shift keying) modulation sent by the reader transmitter.

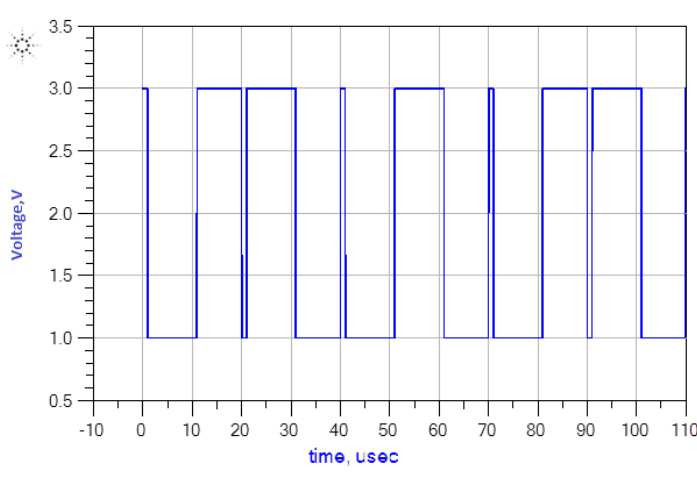

Fig. 3. Digital data to be transmitted.

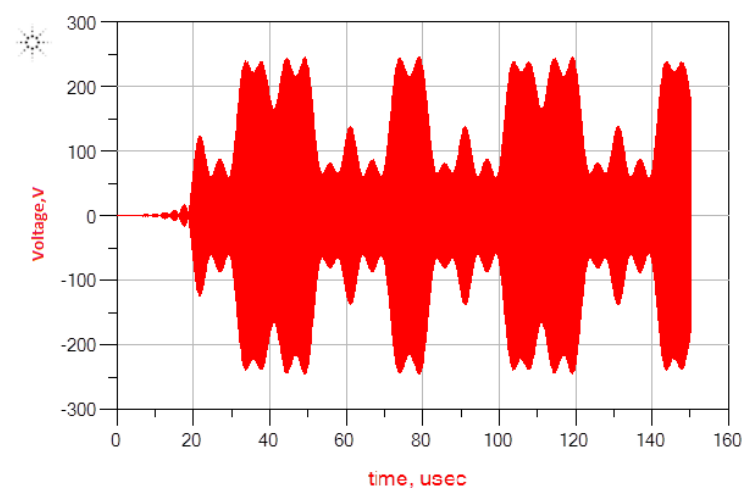

Fig. 4. Carrier modulated by the data.

Considering the operational working, the modulated signal is transmitted to the tag, which returns its coded identification. In order to simulate this process, the tag is considered as a data autonomous source. Figure 5 shows the encoded data sent by the tag (point $\mathrm{C}$ on Figure 1). Figure 6 (point D on Figure 1) shows the demodulated 
signal using the encoding according to Class 1 protocol. The data represent the binary sequence "111111100100001...". The modulated signal is transmitted through the compensation block. The data are thus available at the output of the receiver circuit. Figure 6 shows that the received data correspond to the data sent by the tag, as we expected.

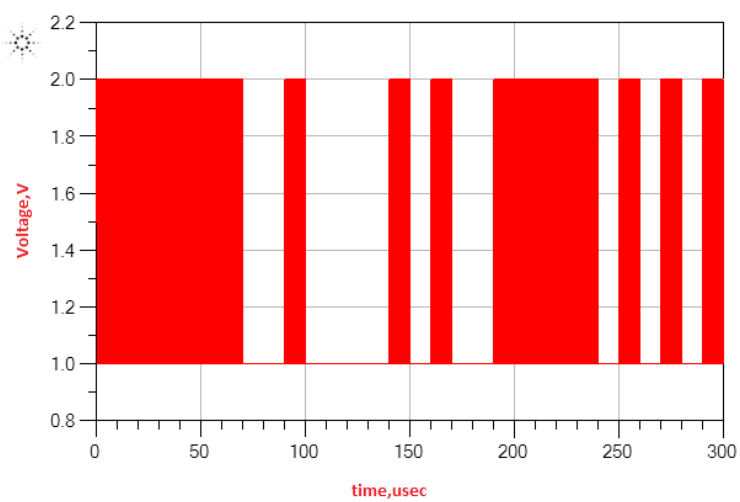

Fig. 5. Signal sent by the tag.

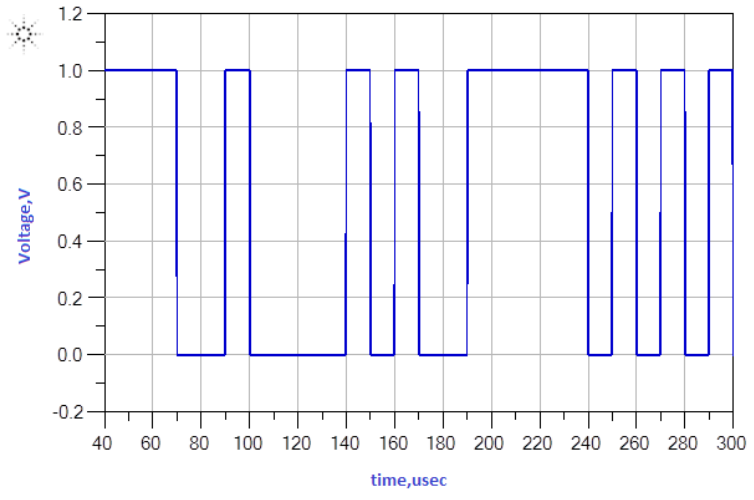

Fig. 6. Signal received by the reader.

\section{Description of measurement bench}

In order to study the robustness and the reliability of passive tags submitted to severe environmental constraints, we have developed the measurement bench shown in Figure 7. The commercial reader SPEEDWAY [8] is controlled by the PC (hot), it is connected to an antenna placed on a turntable $360^{\circ}$. The tag to be tested is placed on a stand disposed on a slide rail for a distance of up to 2 meters. Placed in an open environment of obstacles, this bench allows readings of the power reflected by the tag depending on the distance.

The bench can operate with four possible frequencies in the UHF band, corresponding to the European standard: $866.30 \mathrm{MHz}-866.90 \mathrm{MHz}-867.5 \mathrm{MHz}$ or $865.7 \mathrm{MHz}$, the emitted power of the reader can reach $30 \mathrm{dBm}$, the gain of the antenna is $6 \mathrm{dBi}$. 


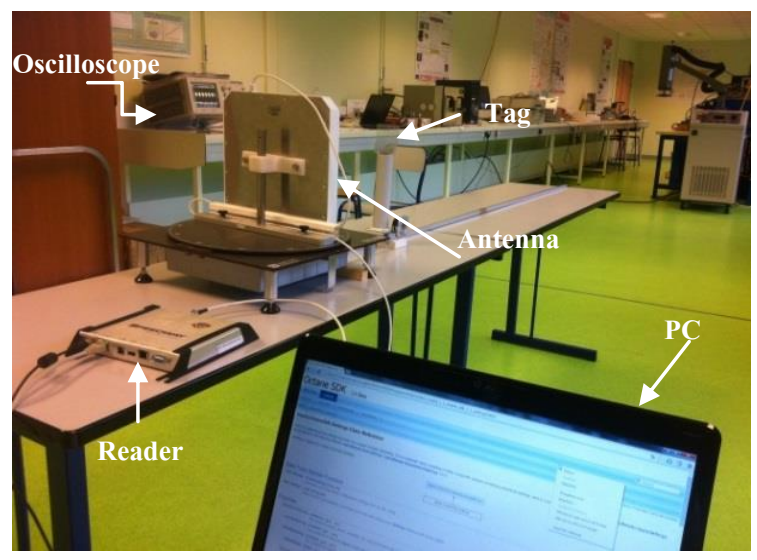

Fig. 7.a. View of the test bench.

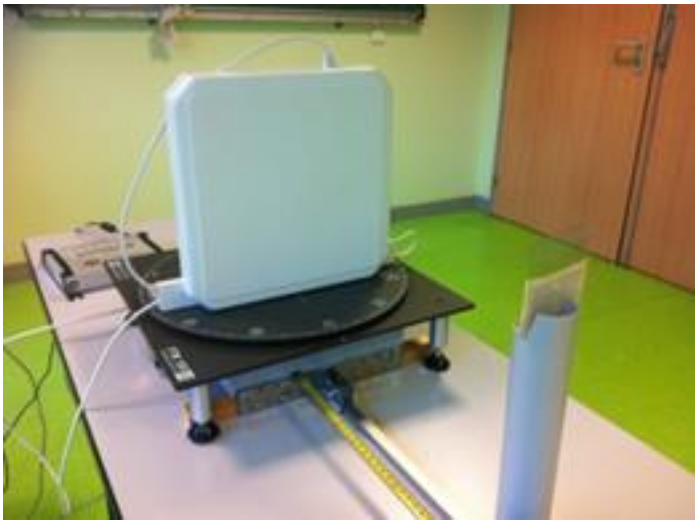

Fig. 7.b. Tag mounted on the sliding support.

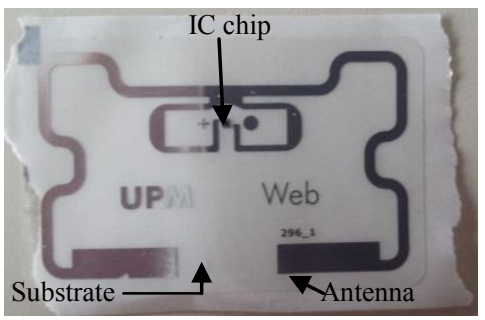

Fig. 7.c. View of the UPM Web tag.

The passive tag chosen under test is shown in Figure.7.c. Its size is $40 \mathrm{~mm} \times 54 \mathrm{~mm}$ and it can be easily attached to the object to be stored. It meets the requirements of EPC Class 1 Generation 2 (Gen 2) ISO $18000-6 \mathrm{C}$, and has an antenna attached to an integrated memory chip containing its unique identifier whose memory is 96 bits, or 12 bytes.

\section{Time measurements for the communication Reader / tag}

Figure 8 shows chronograms recorded using the oscilloscope "Agilent Infinium" with a $6 \mathrm{GHz}$ bandwidth, covering the UHF range. Figure 8 shows the signal sent by the reader with the presence of a tag placed in the reading field. As expected, a DSB-ASK modulation signal measured.

As shown in chronograms, part A of the signal represents the continuous wave $(\mathrm{CW})$ signal suitable to feed the tag. Part B represents the instruction sent to the tag.

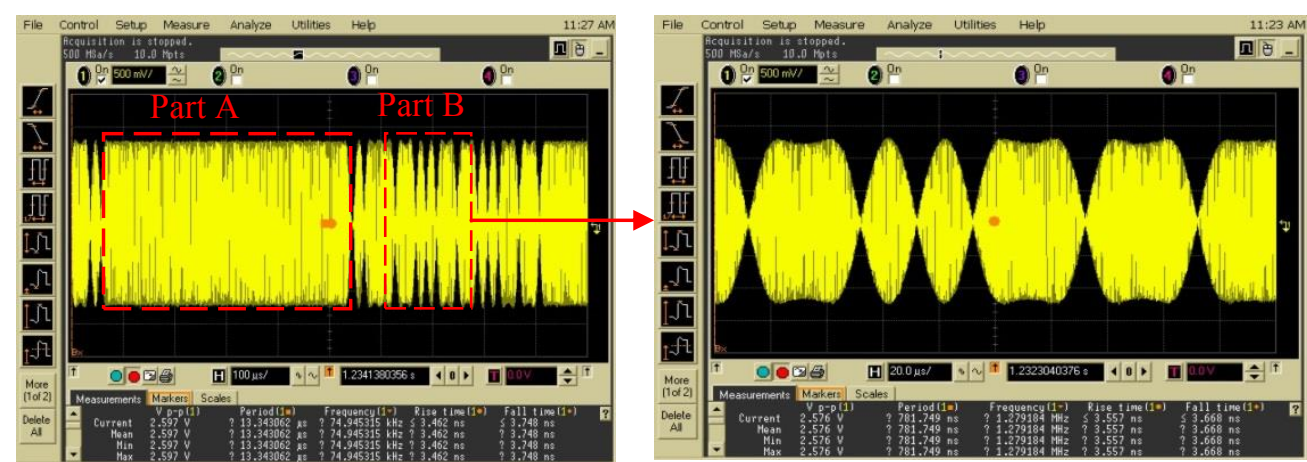

Fig. 8. Time measurements for communication between reader / tag. 


\section{Experimental results for tag reliability study}

\subsection{Experimental process conditions}

In this section some tests on tags are performed and presented, using the bench describe in paragraph 4 . The operating frequency band depends mainly on the RFID reader used. The working frequency is equal to $865.7 \mathrm{MHz}$. The reader generates a radio frequency signal transmitted by a coaxial cable to the antenna. The tag under test is positioned on a rail. The distance can be adjusted in a $200 \mathrm{~cm}$ range. The tag receives the signal and returns its identification code, the reflected power measured and displayed on the screen of a PC connected to the RFID reader.

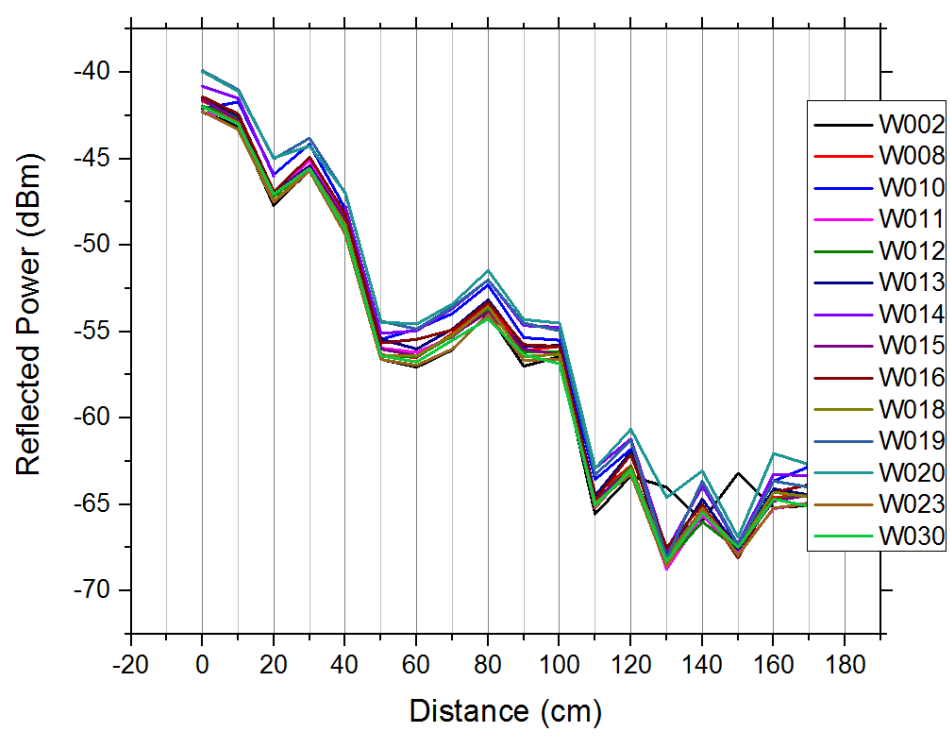

Fig. 9. Reflected power by the tags vs distance.

To get representative values, fourteen fresh tags for first series were tested. The results of these tests are shown in Figure 9. The power emitted by the reader is fixed to $27 \mathrm{dBm}$. The measurements reveal no significant variations of the reflected power (standard deviation $2.07 \%$ ) for the different tags, showing a similar behavior. These results show that the bench is fully operational to meet the needs of this study.

\subsection{Aging reliability tests}

Passive UHF RFID tags are used for object identification in various environmental conditions which may affect their reliability $[9,10]$. In order to evaluate the degradation of the performances, the effect of different temperatures is studied [11]. 
According to the manufacturer [12] the tags under study can operate efficiently in the temperature range between $-40{ }^{\circ} \mathrm{C}$ and $85^{\circ} \mathrm{C}$. To study the impact of accelerated life tests, storages under high temperatures are performed on three tags. The starting temperature was set at $100{ }^{\circ} \mathrm{C}$ corresponding to an overtaking close to $20 \%$ of the maximum value recommended by the manufacturer. The selected step is $20^{\circ} \mathrm{C}$; storage time is 72 hours by step. The results for storage temperatures are shown in Figure 10.

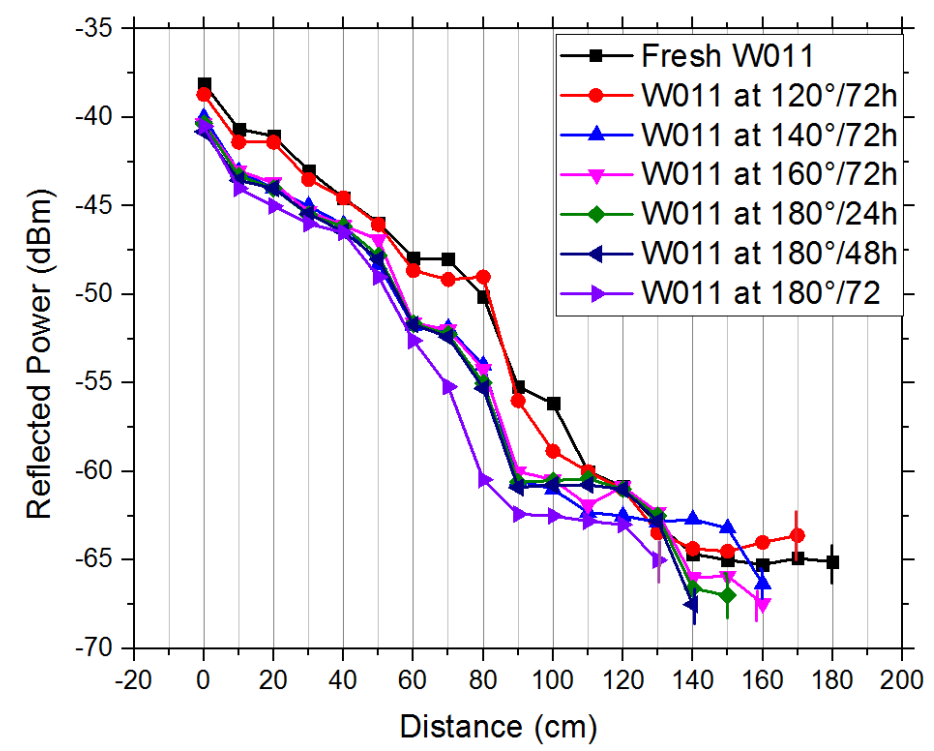

Fig. 10. Reflected power by W011 vs distance

The performance parameters of the tag are significantly changed during the tests, the reflected power decreases after each test which strongly influence the range of the tag. Harder accelerated life tests are underway and the stress levels are in progress to accelerate the failures mechanisms.

\section{Conclusion and perspectives}

The purpose of this work is to study the robustness and reliability of RFID systems in the UHF band under stern environmental conditions. A failure analysis will be implemented in order to determine accurately the type of defect. Moreover, the metallization of the antenna should be examined with an optical microscope to identify any cracks which will affect the performance of the tags. In addition, with a series of thirty devices, a statistical analysis using the predicted reliability calculation tools should be implemented to determine the mechanisms failures acceleration. Based on the simulations developed under ADS software, our objective is developing a reader based on discrete components. The system will be able to communicate with 
the tags that will be tested by varying the transmit power and the frequency throughout the whole UHF band.

\section{References}

1. Agilent EEsof EDA, Advanced Design System, The Industry's Leading RF, Microwave and High-Speed Design Platform.

2. D. Dobkin, "The RF in RFID Passive UHF RFID in practice", Editor Elsevier, ISBN: 97807506-8209-1, 2008.

3. Ming K. Lim, Witold Bahr, Stephen C.H. Leung, "RFID in the warehouse: A literature analysis (1995-2010) of its applications, benefits, challenges and future trends." International Journal of Production Economics, Volume 145, Issue 1, Pages 409430,September 2013.

4. P. Hauet. L'identification par radiofréquence (RFID) techniques et perspectives, article invité, REE No.10, Novembre 2006.

5. ЕPCTM Radio-Frequency Identity Protocols, Generation-2 UHF RFID, Specification for RFID Air Interface, Protocol for Communications at $860 \mathrm{MHz}-960 \mathrm{MHz}$.Version 2.0.0 Ratified.

6. Bin You, Bo Yang, Xuan Wen,andLiangyu Qu, "Implementation of Low-Cost UHF RFID Reader Front-Ends with Carrier Leakage Suppression Circuit", International Journal of Antennas and Propagation, Article ID 135203, 8 pages, 2013.

7. L. Jin, T. Cheng, “Analysis and Simulation of UHF RFID System”, IEEE ICSP2006 Proceedings, 2006.

8. UHF GEN 2 RFID,SpeedwayR installation and operations guideversion 5.2, Copyright (C) 2012 - 2014 Impinj, Inc. All rights reserved,http://www.impinj.com.

9. P. Viswanadham and P. Singh, Failure Modes and Mechanism in Electronic Packages. London, U.K.: Chapman \& Hall, 1998, 370 pp.

10. E. Suhir, "Accelerated life testing (ALT) in microelectronics and photonics: Its role, attributes, challenges, pitfalls, and interaction with qualification tests," ASME J. Electron. Packag., vol. 124, no. 3, pp. 281-291,2002.

11. SannaLahokallio, Kirsi Saarinen-Pulli, Laura Frisk, Effects of different test profiles of temperature cycling tests on the reliability of RFID tags, Microelectronics Reliability, Volume 55, Issue 1, January 2015, Pages 93-100, ISSN 0026-2714.

12. UPM RFID, Datasheet web-RFID-Tag, EPCglobal. www.upmrfid.com 